\title{
PARTISIPASI ANGGOTA KELOMPOK TANI DALAM PROGRAM UPSUS PAJALE DI KECAMATAN NATAR KABUPATEN LAMPUNG SELATAN
}

\section{Participation of Farmer Group Members in Upsus Pajale Program in Natar District, South Lampung Regency}

\author{
Oleh: \\ Ochi Ramadhani ${ }^{1 *}$, Tubagus Hasanuddin ${ }^{2}$, Indah Listiana ${ }^{2}$ \\ ${ }^{1}$ Jurusan Agribisnis, Fakultas Pertanian, Universitas Lampung. \\ ${ }^{2}$ Program Studi Penyuluhan Pertanian, Fakultas Pertanian, Universitas Lampung. \\ J1.Sumantri Brojonegoro 1, Bandar Lampung, 35145, Lampung, Indonesia \\ *email: ochirmd@gmail.com
}

Received September 23, 2020; Revised December 11, 2020; Accepted December 18, 2020

\begin{abstract}
ABSTRAK
Tujuan penelitian ini adalah untuk mengetahui tingkat partisipasi dan faktor-faktor yang berhubungan dengan tingkat partisipasi petani dalam program Upsus Pajale. Penelitian ini dilakukan di Kecamatan Natar, Kabupaten Lampung Selatan. Sampel dalam penelitian ini berjumlah 45 responden petani yang dipilih secara acak. Penelitian ini dilakukan pada bulan November - Desember 2018. Penelitian ini dilakukan dengan menggunakan metode survei. Analisis data menggunakan analisis deskriptif dan uji korelasi Rank Spearman. Hasil penelitian ini menunjukkan bahwa Tingkat partisipasi anggota kelompok tani dalam perencanaan kegiatan sebagian besar tergolong sedang $(53,56 \%)$, partisipasi dalam pelaksanaan kegiatan sebagian besar tergolong tinggi $(53,33 \%)$, partisipasi dalam pemantauan dan evaluasi kegiatan tergolong tinggi $(62,22 \%)$, dan partisipasi dalam pemanfaatan hasil kegiatan tergolong sedang $(53,33 \%)$. Secara keseluruhan sebagian besar partisipasi anggota kelompok tani dalam Program Upsus Pajale tergolong tinggi (53,33\%). Faktor-faktor yang berhubungan dengan tingkat partisipasi petani dalam program Upsus Pajale, yaitu motivasi, tingkat pengetahuan, dan persepsi petani.
\end{abstract}

Kata Kunci : Kelompok Tani, Partisipasi, Upsus Pajale.

\section{ABSTRACT}

The purpose of this study was to determine the level of farmer participation in the Upsus Pajale program and the factors related to the level of farmer participation in the Upsus Pajale program. This research was conducted in Natar District, South Lampung Regency. The sample in this study amounted to 45 farmer respondents who were randomly selected. This research was conducted in November - December 2018. This research was conducted using a survey method. Data analysis used descriptive analysis and Rank Spearman correlation test. The results of this study indicate that the level of participation of farmer group members in planning activities. most of them were classified as moderate (53.56\%), participation in the implementation of activities was mostly classified as high (53.33\%), participation in monitoring and evaluation of activities was high (62.22\%), and participation in the utilization of activity results was classified as moderate (53.33\%). Overall, most of the participation of farmer group members in the Upsus Pajale Program is high (53.33\%. Factors related to the level of farmer participation in the Upsus Pajale program, namely motivation, level of knowledge, and perception of farmers

Keywords: Farmer Group, Participation, Upsus Pajale. 


\section{PENDAHULUAN}

Indonesia merupakan salah satu negara yang memiliki tingkat pertumbuhan penduduk yang relatif besaryaitu sebesar 3,51 persen penduduk dunia atau 255,5 juta/jiwa dibandingkan negara asean lainnya seperti Negara Filipina 1,41 persen atau 102,5 juta/jiwa (BPS, 2013). Peningkatan jumlah penduduk ini akan berdampak terhadap peningkatan kebutuhan pangan masyarakat, oleh karena itu produksi tanaman pangan harus ditingkatkan agar ketahanan pangan dapat terwujud (Hartanti dkk, 2012).

Ketahanan pangan telah menjadi isu global selama dua dekade terakhir termasuk di Indonesia. Berdasarkan Undang - undang No 18 tahun 2012 tentang Pangan disebutkan bahwa "Ketahanan Pangan adalah kondisi terpenuhinya pangan bagi negara sampai dengan perseorangan, yang tercermin dari tersedianya pangan yang cukup, baik jumlah maupun mutunya, aman, beragam, bergizi, merata, dan terjangkau serta tidak bertentangan dengan agama, keyakinan, dan budaya masyarakat, untuk dapat hidup sehat, aktif, dan produktif secara berkelanjutan".

Pemenuhan kebutuhan produk pangan bagi rakyat merupakan tugas pemerintah yang tidak ringan. Hal ini dapat dilihat dari luas tanam yang semakin berkurang karena alih fungsi lahan pertanian menjadi nonpertanian, kualitas benih yang kurang baik, hama dan penyakit tanaman yang diakibatkan oleh dampak dari perubahan iklim, sehingga produksi yang dihasilkan kurang baik, dan berdampak pada daya saing produk dalam negeri menjadi lemah. Hal ini antara lain yang menyebabkan perlu dilakukannya kegiatan impor produk pangan seperti padi, jagung, dan kedelai.

Provinsi Lampung merupakan salah satu daerah sentra produksi pangan yang melaksanakan Program Upsus Pajale. Kabupaten Lampung Selatan merupakan salah satu kabupaten di Provinsi Lampung yang ikut berpartisipasi dalam Program Upsus Pajale. Kabupaten Lampung Selatan memiliki produksi padi terbesar ketiga setelah Kabupaten Lampung Tengah dan Lampung Timur, dan produktivitas padi Kabupaten Lampung Selatan lebih besar jika dibandingkan dengan Kabupaten Lampung Timur dengan produksi padi sebesar 579.534 ton dan produktivitas sebesar 5,46 ton/ha per tahun. Produksi Jagung menempati urutan tertinggi kedua setelah Kabupaten Lampung Timur dengan produksi sebesar 690.785 ton dan produktivitas sebesar 5,40 ton/ha. Namun untuk produksi kedelai di Kabupaten Lampung Selatan menduduki urutan tertinggi kelima dengan produksi sebesar 511 ton dan produktivitas sebesar 1,30 ton/ha.

Kecamatan Natar merupakan salah satu kecamatan di Kabupaten Lampung Selatan yang memiliki luas panen, produksi dan produktivitas tanaman padi dan jagung yang cukup tinggi dalam pelaksanaan Program Upsus Pajale. Produksi Padi di Kecamatan Natar menduduki urutan tertinggi ketiga setelah Kecamatan Palas dan Kecamatan Candipuro dengan luas panen sebesar 9.106 ha dan produksi sebesar 49.966 ton dengan produktivitas 5,49 ton/ha. Produksi Jagung di Kecamatan Natar menduduki urutan tertinggi keempat setelah Kecamatan Penengahan, Kecamatan Ketapang dan Kecamatan Kalianda yang memiliki luas panen sebesar 12.252 ha dan produksi sebesar 65.756 ton dengan produktivitas 5,37 ton/ha.

Untuk menunjang terlaksananya pembangunan pertanian dalam Program Upsus Pajale diperlukan adanya partisipasi aktif dari pemerintah dan sasaran. Sasaran dalam program ini adalah kelompok tani atau gapoktan yang berusahatani tanaman pangan seperti komoditi padi, jagung dan kedelai. Partisipasi adalah keikutsertaan atau keterlibatan individu dalam suatu kegiatan pembangunan baik dari tahap perencanaan, pelaksanaan, pengawasan dan evaluasi, serta ikut menikmati dan memanfaatkan hasilhasil dari pembangunan tersebut (Mardikanto, 2010). Menurut Slamet (2003), tingkat keberhasilan pembangunan nasional ditentukan oleh tingkat partisipasi dari masyarakat secara keseluruhan, baik dalam menyumbangkan masukan (input), 
pelaksanaan program pembangunannya maupun dalam hal menikmati hasilnya. Oleh karena itu, keberhasilan Program Upsus Pajale pun akan ditunjang oleh tingkat partisipasi dari pemerintah maupun petani sasarannya, tidak terkecuali keberhasilan Program Upsus Pajale yang ada di Kecamatan Natar. Berdasarkan uraian tersebut, maka tujuan dari penelitian ini adalah untuk mengetahui tingkat partisipasi petani dan faktor-faktor yang berhubungan dengan tingkat partisipasi petani dalam program Upsus Pajale di Kecamatan Natar Kabupaten Lampung Selatan.

\section{METODE PENELITIAN}

Metode penelitian yang digunakan adalah metode survey, yaitu penelitian yang mengambil sampel dari suatu populasi dan menggunakan kuesioner sebagai alat pengumpulan data yang pokok (Singarimbun, 1995). Data yang digunakan dalam penelitian ini meliputi data primer dan data sekunder. Data primer diperoleh melalui wawancara langsung dengan anggota kelompok tani di Desa Negara Ratu dan Desa Sidosari yang mengikuti Program Upsus Pajale. Data sekunder diperoleh dari dinas atau instansi terkait dan lembaga-lembaga yang berhubungan dengan penelitian ini. Pengumpulan data dilakukan dengan beberapa teknik yaitu : wawancara langsung dan dokumentasi. Penelitian ini dilakukan pada bulan November - Desember 2018.

Responden penelitian adalah petani peserta Program Upsus Pajale di Kecamatan Natar Kabupaten Lampung Selatan. Pengambilan sampel diambil dari dua desa yaitu Desa Sidosari, Desa Negara Ratu. Jumlah populasi petani padi dan jagung di dua desatersebut berjumlah 111 orang. Metode pengambilan petani sampel dilakukan dengan metode simple random sampling (acak sederhana) yaitu metode yang digunakan untuk memilih sampel dari populasi dengan cara sedemikian rupa sehingga setiap anggota populasi mempunyai peluang yang sama besar untuk diambil sebagai sampel (Sugiarto dkk 2003) dengan rumus sebagai berikut:

$$
\begin{aligned}
& \mathrm{n}=\frac{\mathrm{NZ}^{2} \mathrm{~S}^{2}}{\mathrm{Nd}^{2}+\mathrm{Z}^{2} \mathrm{~S}^{2}} \\
& \mathrm{~N}=\text { Jumlah sampel } \\
& \mathrm{N}=\text { Jumlah populasi petani } \\
& \mathrm{Z}=\text { Tingkat kepercayaan }(95 \%=1,96) \\
& \mathrm{S}^{2}=\text { Variasi sampel }(5 \%=0,05) \\
& \mathrm{d} \quad=\text { Derajat penyimpangan }(5 \%=0,05)
\end{aligned}
$$

Berdasarkan perhitungan dengan rumus diatas, diperoleh jumlah sampel untuk petani yang mengikuti Program Upsus Pajale di Kecamatan Natar adalah 45 responden.

Metode analisis data yang digunakan pada penelitian ini adalah metode deskriptif kuantitatif. Metode pengolahan data dilakukan dengan menggunakan metode tabulasi dan statistika non parametrik korelasi Rank Spearman. Pengujian hipotesis pada penelitian ini menggunakan statistik non parametrik korelasi Rank Spearman (Siegel, 1997)

$$
\frac{6 \sum_{i=1}^{n} d i^{2}}{n^{3}-n}
$$
Keterangan:
rs $=$ Koefisien korelasi
$\mathrm{di}=$ Perbedaan pasangan setiap peringkat
$\mathrm{n}=$ Jumlah sampel

\section{HASIL DAN PEMBAHASAN}

\section{Gambaran Umum Kecamatan Natar}

Kecamatan Natar merupakan kecamatan terluas di Lampung Selatan yaitu sekitar 12 persen dari total luas Lampung Selatan. Sebelah utara Kecamatan Natar berbatasan dengan Kecamatan Tegineneng Kabupaten Pesawaran, sebelah timur berbatasan dengan Kecamatan Jati Agung, sebelah selatan berbatasan dengan Kota madya Bandar Lampung serta sebelah barat berbatasan dengan Kecamatan Tegineneng Kabupaten Pesawaran. 
Kecamatan Natar terdiri dari 26 desa.Ketinggian desa-desa di Kecamatan Natar rata-rata di bawah $100 \mathrm{~m}$ dari permukaan laut. Topografi di kecamatan ini berupa dataran dan banyak di manfaatkan untuk lahan pertanian. Sebagian besar masyarakat bekerja sebagai petani. Kecamatan Natar termasuk kecamatan yang berpotensi di Kabupaten Lampung Selatan (BPS Kabupaten Lampung Selatan, 2016).

\section{Partisipasi Petani dalam Program Upsus Pajale}

\section{Perencanaan Kegiatan}

Partisipasi masyarakat dalam perencanaan kegiatan perlu ditumbuhkan melalui dibukanya forum yang memungkinkan masyarakat berpartisipasi langsung dalam proses perencanaan tentang program-program pembangunan di wilayah setempat atau di tingkat lokal. Tabel 1 menunjukkan tingkat partisipasi petani dalam perencanaan Program Upsus Pajale berada pada klasifikasi sedang yaitu sebesar(55,56\%) dengan nilai rata-rata 9,00. Hal ini karenak petani masih kurang ikutserta dalam mengikuti perencanaan kegiatan, seperti kurang mengikuti rapat penyusunan Rencana Definitif Kelompok (RDK) atau penyusunan Rencana Definitif Kebutuhan Kelompok (RDKK), kurang memberikan masukan setiap perencanaan program, jugajarang mengikuti pertemuan yang dilakukan dalam mengidentifikasi masalah yang terdapatdalam program, dan sedikit petani yang terlibat dalam pengambilan keputusan. Tingkat partisipasi petani dalam perencanaan Program Upsus Pajale ditampilkan pada Tabel 1.

\section{Tabel 1.}

Sebaran partisipasi petani dalam perencanaan Program Upsus Pajale

\begin{tabular}{clcc}
\hline Skor & Klasifikasi & $\begin{array}{c}\text { Responden } \\
(\text { Orang) }\end{array}$ & $\begin{array}{c}\text { Persentase } \\
(\%)\end{array}$ \\
\hline $4,00-6,66$ & Rendah & 2 & 4,44 \\
$6,67-9,33$ & Sedang & 25 & 55,56 \\
$9,34-12,00$ & Tinggi & 18 & 40,00 \\
\hline Total & & 45 & 100,00 \\
\hline \multicolumn{2}{c}{ Rata-rata $=9,00($ Sedang) } \\
\hline
\end{tabular}

\section{Pelaksanaan Kegiatan}

Partisipasi masyarakat dalam pelaksanaan pembangunan harus diartikan sebagai pemerataan sumbangan masyarakat dalam bentuk tenaga kerja, uang-tunai, dan atau berbentuk korbanan lainnya yang sepadan dengan manfaat yang diterima oleh masing-masing warga masyarakat yang bersangkutan. Tabel 2 menunjukkan bahwa partisipasi petani dalam pelaksanaan kegiatan Program Upsus Pajale berada pada klasifikasi tinggi yaitu sebesar 53,33\%, dengan nilai rata-rata 12,00 . Hal ini seajalan dengan penelitian Listiana (2010) yang menyatakan bahwa partisipasi peternak sapi dalam kegiatan kemitraan berada pada klasifikasi tinggi.

\section{Tabel 2.}

Partisipasi petani dalam pelaksanaan kegiatan Program Upsus Pajale

\begin{tabular}{cccc}
\hline Skor & Klasifikasi & $\begin{array}{c}\text { Responden } \\
(\text { Orang })\end{array}$ & $\begin{array}{c}\text { Persen } \\
(\%)\end{array}$ \\
\hline $5,00-8,33$ & Rendah & 4 & 8,89 \\
$8,34-11,67$ & Sedang & 17 & 37,78 \\
$11,68-15,00$ & Tinggi & 24 & 53,33 \\
\hline Total & & 45 & 100,00 \\
\hline Rata-rata $=12,00$ (Tinggi) & & \\
\hline
\end{tabular}

\section{Pemantauan dan Evaluasi}

Kegiatan pemantauan dan evaluasi program pembangunan sangat diperlukan supaya tujuannya dapat dicapai seperti yang diharapkan, dan memperoleh umpan balik tentang masalah serta kendala yang muncul dalam pelaksanaan pembangunan yang bersangkutan. Tabel 3 menunjukkan bahwa tingkat partisipasi petani dalam pemantauan dan evaluasi. Program Upsus Pajale terbanyak berada pada klasifikasi tinggi $(62,22 \%)$ dengan nilai rata-rata 12,00 . Kegiatan yang dilakukan petani dalam menilai dan mengevaluasi Program Upsus Pajale yaitu meliputi pengawasan terhadap benih unggul, bantuan pupuk, bantuan alat mesin pertanian, sehingga petani dapat menilai untuk keberlanjutan Program Upsus Pajale dimassa yang akan datang. Tingkat partisipasi petani dalam pemantauan dan evaluasi kegiatan Program Upsus Pajale dijelaskan dalam Tabel 3. 
Tabel 3.

Partisipasi petani dalam pemantauan dan evaluasi kegiatan Program Upsus Pajale

\begin{tabular}{cccc}
\hline Skor & Klasifikasi & $\begin{array}{c}\text { Responden } \\
(\text { Orang })\end{array}$ & $\begin{array}{c}\text { Persentase } \\
(\%)\end{array}$ \\
\hline $5,00-8,33$ & Rendah & 4 & 8,89 \\
$8,34-11,67$ & Sedang & 13 & 28,89 \\
$11,68-15,00$ & Tinggi & 28 & 62,22 \\
\hline Total & 45 & 100,00 \\
\hline Rata-rata $=12,00$ (Tinggi) & & \\
\hline
\end{tabular}

\section{Pemanfaatan Hasil Program}

Partisipasi dalam pemanfaatan hasil pembangunan suatu program sering terlupakan.Sebab, tujuan pembangunan adalah untuk memperbaiki mutu hidup masyarakat sehingga pemerataan hasil pembangunan merupakan tujuan utama.

Tabel 4.

Sebaran partisipasi petani dalam pemanfaatan hasil Program Upsus Pajale

\begin{tabular}{cccc}
\hline Skor & Klasifikasi & $\begin{array}{c}\text { Responden } \\
(\text { Orang) }\end{array}$ & $\begin{array}{c}\text { Persentase } \\
(\%)\end{array}$ \\
\hline $3,00-5,00$ & Rendah & 7 & 15.56 \\
$5,01-7,00$ & Sedang & 24 & 53.33 \\
$7,01-9,00$ & Tinggi & 14 & 31.11 \\
\hline Total & & 45 & 100,00 \\
\hline Rata-rata $=7,00$ (Sedang) & & \\
\hline
\end{tabular}

Tabel 4 menunjukkan bahwa tingkat partisipasi petani dalam pemanfaatan hasil Program Upsus Pajale berada pada klasifikasi sedang dengan nilai rata-rata 7,00. Hal ini dikarenakan petani kurang merasakan manfaat adanya program seperti sulitnya petani dalam memperoleh bantuan benih, ketersediaan pupuk yang terlambat, sulitnya dalam peminjaman alat pertanian, serta kurangnya komunikasi antar PPL dan petani.

Faktor-faktor yang Berhubungan dengan Partisipasi Petani dalam Program Upsus Pajale

Aktivitas-aktivitas atau kegiatan di dalam suatu Program Upsus Pajale tidak akan berjalan dengan baik apabila tidak didukung oleh partisipasi dari anggota Upsus Pajale yang baik pula. Berikut penjelasan mengenai faktor-faktor yang berhubungan dengan partisipasi petani Program Upsus
Pajale di Kecamatan Natar Kabupaten Lampung Selatan

\section{Motivasi Petani}

Berkaitan dengan motivasi petani mengikuti Program Upsus Pajale, maka terdapatnya program ini diharapkan dapat memotivasi petani dalam menjalankan program upsus pajale serta mewujudkan tujuan yang ingin dicapai dalam meningkatkan usahatani. Tabel 5 menunjukkan bahwa tingkat motivasi petani terhadap program upsus pajale berada pada klasifikasi tinggi dengan nilai rata-rata 14,82. Hal ini tidak terlepas dari peranan penyuluhan pertanian dalam pelaksanaan kegiatan tersebut. Menurut Listiana (2018), motivasi penyuluh pertanian untuk bekerja cenderung tinggi. Berdasarkan penelitian yang telah dilakukan, dijumpai sebanyak 27 orang responden $(60,00 \%)$ menyatakan bahwa tingkat motivasi petani berada pada klasifikasi tinggi, dan petani termotivasi dengan adanya sosialisasi yang dilakukan oleh penyuluh terkait program upsus pajale untuk mengikuti program tersebut agar meningkatkan produksi dan produktivitas.

Tabel 5.

Tingkat motivasi petani tentang Program Upsus Pajale

\begin{tabular}{|c|c|c|c|}
\hline Skor & Klasifikasi & $\begin{array}{c}\text { Responden } \\
\text { (Orang) }\end{array}$ & $(\%)$ \\
\hline $14,01-18,00$ & Tinggi & 27 & 60,00 \\
\hline $10,01-14,00$ & Sedang & 15 & 33,33 \\
\hline $6,00-10,00$ & Rendah & 3 & 6,67 \\
\hline Total & & 45 & 100,00 \\
\hline \multicolumn{4}{|c|}{ Rata-rata $=14,82$ (Sedang) } \\
\hline
\end{tabular}

\section{Tingkat Pengetahuan Petani}

Pengetahuan petani mengenai Program Upsus Pajale meliputi pengetahuan petani tentang tujuan, ruang lingkup, pendanaan, dan struktur organisasi pelaksanaan Program Upsus Pajale berkaitan dengan partisipasi petani. Tabel 6 menunjukkan bahwa tingkat pengetahuan petani tentang Program Upsus Pajale berada pada klasifikasi sedang dengan nilai rata-rata 13,04. Hal ini sejalan dengan penelitian Anggraini (2019) yang menyatakan bahwa tingkat pengetahuan 
petani tentang program PUPM berada pada klasifikasi tinggi. Sebanyak 24 orang responden $(53,33 \%)$ menyatakan bahwa tingkat pengetahuan petani tentang Program Upsus Pajale berada pada klasifikasi sedang. Petani cukup mengetahui tentang Program Upsus Pajalekarena dari penyuluh pertanian lapangan maupun dari ketua kelompok tani cukup sering memberi informasi tentang tujuan, ruang lingkup, dan sistem pendanaan pada program upsus pajale.

Tabel 6.

Tingkat pengetahuan petani tentang Program Upsus Pajale

\begin{tabular}{llcc}
\hline \multicolumn{1}{c}{ Skor } & Klasifikasi & $\begin{array}{c}\text { Responden } \\
(\text { Orang) }\end{array}$ & $\begin{array}{c}\text { Persen } \\
(\%)\end{array}$ \\
\hline $14,01-18,00$ & Tinggi & 10 & 22,22 \\
$10,01-14,00$ & Sedang & 24 & 53,33 \\
$6,00-10,00$ & Rendah & 11 & 24,44 \\
\hline Total & & 45 & 100,00 \\
\hline Rata-rata $=13,04$ (Sedang) & &
\end{tabular}

\section{Persepsi Petani}

Persepsi petani berhubungan dengan partisipasi petani karena semakin baik persepsi petani maka semakin baik partisipasi petani pada suatu program. Tabel 7 menunjukkan bahwa Tingkat persepsi petani tentang program upsus pajale berada pada klasifikasi baik dengan nilai rata-rata 14,13 . Hal ini sejalan dengan penelitian Tati (2014) yang menyatakan bahwa persepsi masyarakat terhadap program kemitraan dan bina lingkungan termasuk dalam kategori tinggi.

\section{Tabel 7.}

Persepsi petani tentang Program Upsus Pajale

\begin{tabular}{clcr}
\hline Skor & Klasifikasi & $\begin{array}{c}\text { Responden } \\
\text { (Orang) }\end{array}$ & Persen (\%) \\
\hline $14,01-18,00$ & Baik & 20 & 44,44 \\
$10,01-14,00$ & Cukup Baik & 15 & 33,33 \\
$6,00-10,00$ & Kurang Baik & 10 & 22,22 \\
\hline \multicolumn{2}{c}{ Total } & 45 & 100,00 \\
\hline \multicolumn{2}{c}{ Rata-rata $=14,13$ (Baik) } & & \\
\hline
\end{tabular}

Sebanyak 20 orang responden $(44,44 \%)$ yang diteliti menyatakan bahwa tingkat persepsi petani tentang program upsus pajale berada pada klasifikasi baik. Hal ini didukung dengan adanya kegiataan pembinan dan pendampingan yang dilakukan oleh PPL. Petani telah merasakan manfaat dari hasil-hasil pembangunan pada program seperti: penggunaan benih unggul, bantuan pupuk, dan hasil panen padi meningkat.

\section{Hasil Pengujian Hipotesis}

Berdasarkan analisis uji statistik yang dilakukan tampak bahwa terdapa thubungan antara motivasi petani (X1) dengan partisipasi petani dalam Program Upsus Pajale (Y) dengan nilai koefisien kolerasi rank spearman $\left(\mathrm{r}_{\mathrm{s}}\right)$ sebesar 0,302 dan nilai signifikansi sebesar 0,044 (lebih kecil dari $\alpha$ $(0,05)$ sehingga dapat diambil keputusan untuk terima $\mathrm{H}_{1}$, artinya motivasi petani berhubungan nyata dengan partisipasi petani dalam Program Upsus Pajale di Kecamatan Natar Kabupaten Lampung Selatan. Hal ini dikarenakan adanya motivasi petani dari faktor eksternal dan internal. Faktor eksternal seperti lingkungan yang cukup mendukung petani dalam menjalankan program Upsus Pajale. Faktor internal seperti dukungan keluarga kepada petani dalam melakukan usahatani, sehingga menyebabkan petani cukup berpartisipasi dalam program upsus pajale.

Selain itu, berdasarkan Tabel 8 tersebut juga tampak bahwa terdapat hubungan antara tingkat pengetahuan petani (X2) dengan partisipasi petani dalam Program Upsus Pajale (Y), yaitu diperoleh nilai koefisien kolerasi rank spearman $\left(\mathrm{r}_{\mathrm{s}}\right)$ sebesar 0,298 dan nilai signifikasi sebesar 0,047 lebih kecil dari $\alpha(0,05)$ sehingga dapat diambil keputusan untuk terima $\mathrm{H}_{1}$, artinya tingkat pengetahuan memiliki hubungan nyata dengan partisipasi petani dalam Program Upsus Pajale.

Hubungan antara persepsi petani terhadap Program Upsus Pajale dan partisipasi petani dalam program tersebut tampak bahwa kedua hal ini berhubungan. Tabel 8 menunjukkan bahwa hubungan antara persepsi petani(X3) dengan partisipasi petani dalam Program Upsus Pajale (Y) diperoleh nilai koefisien kolerasi rank spearman $\left(r_{s}\right)$ sebesar 0,325dan nilai signifikasi sebesar 0,029 lebih kecil dari $\alpha$ $(0,05)$. Hal ini menunjukkan bahwa 
terdapathubungan antara tingkat pengetahuan anggota (X2) dengan partisipasi petani dalam Program Upsus Pajale (Y), artinya persepsi memiliki hubungan nyata dengan partisipasi petani dalam Program Upsus Pajale. Tabel 8 berikut ini menunjukkan hubungan antara motivasi petani, tingkat pengetahuan dan persepsi petani terhadap Program Upsus Pajale dengan Tingkat partisipasi petani dalam program tersebut.

Tabel 8.

Hasil analisis faktor-faktor yang berhubungan dengan partisipasi petani

\begin{tabular}{|c|c|c|c|c|}
\hline No & Variabel X & $\begin{array}{l}\text { Variabel } \\
\text { Y }\end{array}$ & $\begin{array}{c}\text { Koefisien } \\
\text { Korelasi } \\
\text { (rs) }\end{array}$ & $\begin{array}{c}\text { Sig } \\
(2- \\
\text { tailed }) \\
\end{array}$ \\
\hline 1. & Motivasi Petani & & 0,302 & 0,044 \\
\hline 2 & $\begin{array}{l}\text { Tingkat } \\
\text { Pengetahuan }\end{array}$ & $\begin{array}{l}\text { Partisipasi } \\
\text { Petani }\end{array}$ & 0,298 & 0,047 \\
\hline 3. & Persepsi & & 0,325 & 0,029 \\
\hline
\end{tabular}

\section{KESIMPULAN}

Tingkat partisipasi anggota kelompok tani dalam Program Upsus Pajale di Kecamatan Natar Kabupaten Lampung Selatan tergolong tinggi $(53,33 \%)$. Faktorfaktor yang berhubungan dengan tingkat partisipasi petani dalam program Upsus Pajale di Kecamatan Natar Kabupaten Lampung Selatan yaitu motivasi, tingkat pengetahuan dan persepsi petani. Kendala yang terdapat dalam pelaksanaan pelaksanaan Program Upsus Pajale yaitu kualitas bantuan benih yang tidak baik, ketersediaan pupuk yang terlambat, dan sulitnya dalam peminjaman alat pertanian yang diberikan pemerintah kepada ketua kelompok tani.

\section{DAFTAR PUSTAKA}

Anggraini R, Rangga KK. dan Hasanudin T. 2019. Partisipasi Petani Dan Keberhasilan Program Pengembangan Usaha Pangan Masyarakat (PUPM) Di Kecamatan
Palas Kabupaten Lampung Selatan. JIIA, Vol. 7, No. 1, Februari 2019.

Badan Pusat Statistik Kabupaten Lampung Selatan. 2016. Kecamatan Natar dalam Angka 2015. Badan Pusat Statistik. Lampung Selatan.

Badan Pusat Statistik Indonesia. 2013. Proyeksi Penduduk Indonesia 20102035. BPS. Jakarta.

Hartanti, Wiwied, Satia N.L. dan Hasudungan B. 2012. Dampak Pertambahan Penduduk, Akses Pangan dan Usaha Pengentasan Kemiskinan terhadap Jumlah Penduduk Miskin di Sumatera Utara. Jurnal Agribisnis, Vol. 10, No. 4, Oktober 2012.

Listiana I. 2018. Hubungan Kapasitas Penyuluh Dengan Kepuasan Petani Dalam Kegiatan Penyuluhan. Jurnal Penyuluhan, Vol 14 No 2, September 2018.

Listiana, I. 2010. Faktor-faktor yang Berpengaruh terhadap Keberhasilan Kemitraan Penggemukan Sapi Potong antara PT. Great Giant Livestock Company (GGLC) dan Peternak Sapi di Kabupaten Lampung Tengah (Tesis). Surakarta. Universitas Sebelas Maret.

Mardikanto. 2010. Konsep Pemberdayaan Masyarakat. Tiga Serangkai. Surakarta.

Musoleha T, Listiana I. dan Hasanudin T. 2014. Persepsi Masyarakat Terhadap Program Kemitraan dan Bina Lingkungan (PKBL) PTPN VII Unit Usaha Rejosari Kecamatan Natar. JIIA, Vol. 2, No. 4, Oktober 2014.

Siegel, Sidney. 1997. Statistik Non Parametrik Untuk Ilmu Sosial. PT Gramedia Pustaka Utama. Jakarta.

Singarimbun, M. 1995. Metode Penelitian Survey. LP3ES. Jakarta.

Slamet M. 2003. Membentuk Pola Perilaku Manusia Pembangunan - Pemikiran Prof. Margono Slamet; Meningkatkan Partisipasi Masyarakat dalam Pembangunan Perdesaan.....editor. Buku. [Cetak]. 
Bogor (ID). IPB Press. ISBN 979- Undang-undang Republik Indonesia Nomor 493-095-4.

Sugiarto, D., Siagian, LT., Sunaryanto. 2003. 18 Tahun 2012. Pangan. 17 Teknik Sampling. PT Gramedia Pustaka Utama. Jakarta.

November 2012. Lembaran Negara Republik Indonesia tahun 2012 nomor 227. Jakarta. 